\title{
Interactive comment on "Spatial and temporal CCN variations in convection-permitting aerosol microphysics simulations in an idealised marine tropical domain" by Céline Planche et al.
}

Anonymous Referee \#2

Received and published: 4 December 2016

The comment was uploaded in the form of a supplement:

http://www.atmos-chem-phys-discuss.net/acp-2016-826/acp-2016-826-RC2-

supplement.pdf

Interactive comment on Atmos. Chem. Phys. Discuss., doi:10.5194/acp-2016-826, 2016. 